\title{
Determination of ethylene by field asymmetric ion mobility spectrometry
}

\author{
Nattapong Chantipmanee ${ }^{1} \cdot$ Peter C. Hauser $^{1}$ (B)
}

Received: 19 May 2020 / Revised: 13 July 2020 / Accepted: 14 July 2020 / Published online: 22 July 2020

(C) The Author(s) 2020

\begin{abstract}
The determination of ethylene with a field asymmetric ion mobility spectrometer, which can easily be constructed in-house, is described. The device makes use of a Krypton lamp for ionization. A rectangular pulse of $500 \mathrm{~V}_{\mathrm{pp}}$ at $1 \mathrm{MHz}$ was employed as separation waveform in the drift tube rather than the commonly used less efficient bisinusoidal waveform. The calibration curve for the range from $670 \mathrm{ppb}_{(V / V)}$ to $67 \mathrm{ppm}_{(\mathrm{V} / \mathrm{V})}$ was found to be highly linear with a correlation coefficient of $\mathrm{r}=0.9999$. The limit of detection was determined as $200 \mathrm{ppb}_{(V / V)}$. The reproducibility was $4 \%$ (relative standard deviation). The device was found to be suitable for the determination of ethylene given off by fruit; 6 types of climacteric fruit were tested, namely apples, bananas, kiwi fruit, nectarines, pears and plums.
\end{abstract}

Keywords Ethylene $\cdot$ Fruit ripening $\cdot$ Field asymmetric ion mobility spectrometry $\cdot$ Differential ion mobility spectrometry

\section{Introduction}

Ethylene is an important hormone in plant life (also known as phytohormone) with particular relevance in the ripening of climacteric fruit [1-5]. Therefore in the storage and transportion of many fruits (e.g. kiwi fruit) ambient ethylene levels need to be kept low, and some fruits (e.g. bananas) are artificially ripened by exposure to ethylene before sale. In the management of the postharvest physiology of fruit thus the monitoring of ethylene is important. As for some fruit levels as low as $10 \mathrm{ppb}_{(V / \mathrm{V})}\left(\mu \mathrm{L} / \mathrm{m}^{3}\right)$ are relevant in ripening [1], its analytical determination can be challenging.

The approaches reported for the determination of ethylene in horticulture have been reviewed in recent years by Cristescu et al. [6], Caprioli and Quercia [1], and $\mathrm{Hu}$ et al. [2]. The most commonly used method is gaschromatography (GC) with mass-spectrometric detection, which gives high selectivity and sensitivity [7]. On the other hand, the method is relatively complex and expensive. Portable GC instruments are available, but these instruments do not always have the required sensitivity [6]. Optical

Peter C. Hauser

Peter.Hauser@unibas.ch

1 Department of Chemistry, University of Basel, Klingelbergstrasse 80, 4056 Basel, Switzerland detection by direct or indirect absorbance measurements in the infrared range $(\sim 10.5 \mu \mathrm{m})$ is another possibility. The most simple configurations are based on direct absorbance measurements using broadband thermal emittors, but these devices tend to lack the necessary selectivity and sensitivity for horticultural applications. Photoacoustic instruments based on laser diodes or quantum cascade lasers (QCLs) can attain good selectivity and limits of detection in the low $\mathrm{ppb}_{(V / \mathrm{V})}$ range [2, 8]. Such instruments are commercially available, but at a cost of at least $€ 20^{\prime} 000$ [2]. Electrochemical devices based on amperometry are much less expensive and can also give good detection limits in the $\mathrm{ppb}_{(V / \mathrm{V})}$ range [9], especially if used with a forced gas flow [10-12]. However, electrochemical methods are inherently less selective and robust than other means.

In this publication an investigation into the use of FAIMS (field asymmetric ion mobility spectrometry, sometimes also termed differential ion mobility spectrometry, DIMS) for the detection of ethylene is reported. We had a previous interest in the determination of this species [10-12], and inspired by a recent report by Chavarria et al. [13] we wanted to investigate if this task could be addressed with an inexpensive in-house constructed ion-mobility spectrometer. FAIMS makes use of the fact that the mobility of ions is not constant at high field strengths. Ions are separated by application of a asymmetrically pulsed high voltage applied perpendicularly to their travel in a gas stream $[14,15]$. To our knowledge, there is no 
previous account of the determination of ethylene by FAIMS, nor by the more standard drift tube ion mobility spectrometry (DTIMS). In fact, Cross et al. [16] described the successful determination of ammonia in presence of ethylene with a DTIMS instrument employing a ${ }^{63} \mathrm{Ni}$ ionizer, but did not observe any peak attributable to ionized ethylene. On the other hand, ethylene is known to be ionized to $\mathrm{C}_{2} \mathrm{H}_{4}{ }^{+}$by irradiation with UV light of an energy higher than $10.5 \mathrm{eV}$ (see for example [17]). The FAIMS instrument employed in the work detailed here features a Krypton photoionization lamp with a photon energy of $10.6 \mathrm{eV}$. It is based on a design recently reported by Chavarria et al. [13], is simple and inexpensive in construction, and can easily be duplicated by interested parties.

\section{Experimental}

The Krypton photoionization lamp (Heraeus PKS106) and its power supply (Heraeus C200) were purchased from BGB (Boeckten, Switzerland). The suction pump with adjustable flow rate (N920 KT.29.18G) is a product of KNF Neuberger (Balterswil, Switzerland) and the high voltage power supply (MCP 350-1250) of FuG Elektronik (Schechen, Germany). The pulse regime was programmed on a function generator (AFG1022) and monitored on an oscilloscope (TDS 2000), both from Tektronix (Beaverton, Oregon, USA). The electronic components for the construction of the circuitries for the high voltage pulsing, the creation of the compensation voltage, and the detector, were purchased from different distributors (Distrelec, Nänikon, Switzerland; Mouser, Munich, Germany and Digikey, Thief River Falls, Minnesota, USA). The Forth programming environment employed on a MSP430G2553 microcontroller (Texas Instruments, Dallas, $\mathrm{TX}$ ), to create the compensation voltage ramp, was the open source package Mecrisp (http://mecrisp.sourceforge.net). The microcontroller was connected to a personal computer via a USB-to-TTL cable from Future Technology Devices International (Glasgow, UK). The graphical user interface running on the computer under the Windows operating system was written in Python (https://www.python.org). The gas flow rate sensor (Omron, D6F-10A6-000) was obtained from RS Components (Wädenswil, Switzerland) and the humidity sensor (LinPicco A05-G) from Innovative Sensor Technology (Ebnat-Kappel, Switzerland). All signals (including those from the auxiliary sensors) were acquired with an ecorder (ED821) data acquisition system from eDAQ (Denistone East, New South Wales, Australia) connected to a personal computer running the Chart software (eDAQ). The data was further processed and visualized with the software package IGOR Pro (Wavemetrics, Portland, OR).

Ethylene in nitrogen at $999.6 \mathrm{ppm}_{(V / \mathrm{V})}$, provided as a compressed gas in a cylinder (PanGas AG, Switzerland), was employed for calibration. The dilute ethylene was fed to the inlet of the FAIMS device to merge with its intake of ambient air (with a temperature of $25 \pm 1{ }^{\circ} \mathrm{C}$ and a relative humidity of $32 \pm 1 \%$ ) at $9.0 \mathrm{~L} \cdot \mathrm{min}^{-1}$. The resulting ethylene concentrations were set by controlling the flow rate of the feed using mass flow controllers. Two models from Bronkhorst (Aesch, Switzerland) with maximum flow rates of 1000 and $10 \mathrm{~mL}$. $\mathrm{min}^{-1}$ (product numbers F-201CV-1 K0-AAD-22-V and FG200CV-AAD-22-V-DA-000) were employed to cover the desired calibration range. The mass flow controllers were operated with software provided by Bronkhorst.

\section{Results and discussion}

\section{Construction of the instrument}

Sketches of the overall set-up and the cell itself built in-house are shown in Fig. 1A and B respectively. As shown in Fig. 1A, the device was connected to a suction pump to draw either the sample or calibration gas mixture through the cell and the gas flow rate was monitored with a flow sensor. The humidity of the gas stream could also be measured with a flow through sensor. For testing and calibration a controlled stream of dilute ethylene in nitrogen from a compressed gas cylinder was mixed with the ambient air drawn into the cell, while for the testing of the fruit the atmosphere contained in sampling bags (see section 3.5) was aspirated. The cell was contained in a grounded metallic case for electric shielding.

The FAIMS cell, schematically shown in Fig. 1B, was constructed based on the design reported by Chavarria et al. and the details can be found in their publication [13]. However, some modifications were made, and these are explained below. Note also, that the lock-in amplifier extension described by the authors was not adopted. Chavarria et al. tested their cell with acetone and xylene standards, but not for the determination of ethylene. The FAIMS device is made from two pieces of standard epoxy printed circuit board material of $1.6 \mathrm{~mm}$ thickness with a copper layer of $35 \mu \mathrm{m}$ and a spacer of $0.3 \mathrm{~mm}$ thickness to form the flow channel. The total length of the device is approximately $65 \mathrm{~mm}$, and it consists of three sections: the ionization region, a separation region of $12 \mathrm{~mm}$ length, and a detection region. For ionization a Krypton UV-lamp was employed. The top electrode of the separation region was connected to the asymmetric high voltage pulse generator responsible for the separation, and the opposite bottom electrode was connected to the compensation voltage circuitry, which allows the scanning. The ions are forced to the Faraday plate detector by the deflection voltage. The low-noise current amplifier connected to the detector plate (constructed according to Chavarria et al. [13]) was set to a gain of $2 \cdot 10^{10} \mathrm{~V} / \mathrm{A}$. 


\section{(a)}
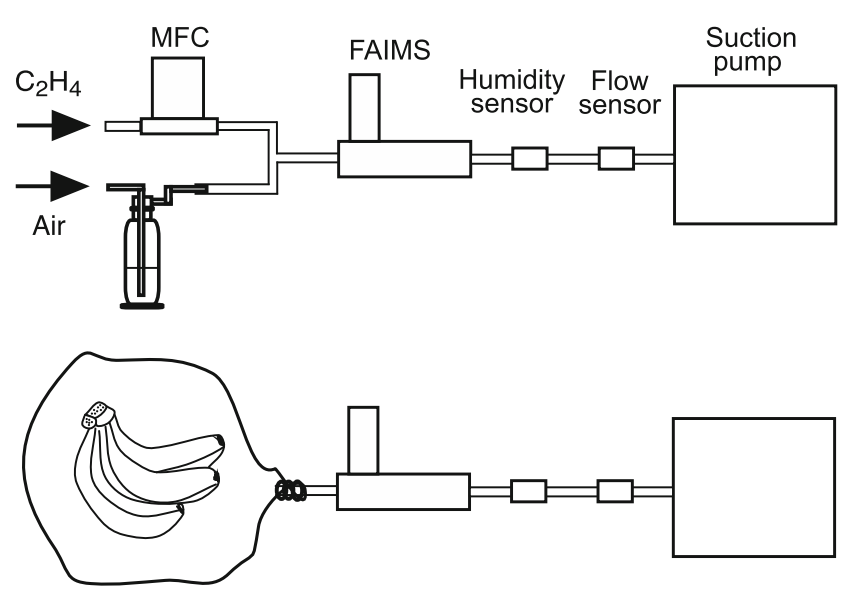

(b)

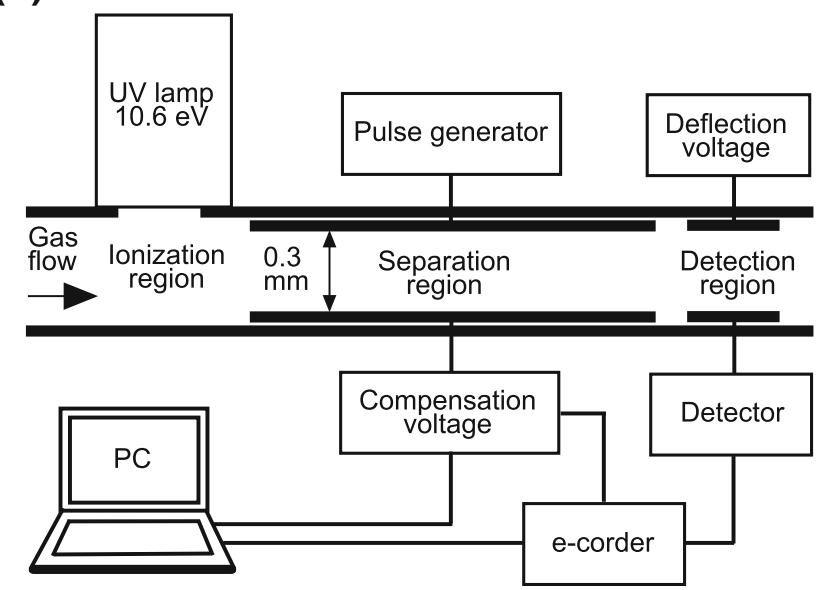

Fig. 1 Schematic diagrams of the FAIMS system (A) Overall set-up showing the arrangements, using a suction pump for drawing gases through the FAIMS cell, for calibration with a mass-flow controller (MFC) and optional moisturization of the diluting air using a Dreschel bottle, as well as for the measurements of the fruit with the sampling bags. B) FAIMS cell.

The instrument employs a rectangular waveform for the high voltage pulsing rather than the commonly used waveform synthesized from two sine waves. This is more efficient as the relevant voltages are applied for extended fractions of time [15]. The circuitries for the pulse generation, based on high voltage field effect transistors (FETs), and the detector amplifier were also constructed according to the circuit diagrams given by Chavarria et al. [13], but the approaches employed for implementing the mobility scan and for data acquisition differ. A simplified schematic of the circuitry employed by us for the sweep of the compensation voltage is given in Fig. 2. It is based on a digital-to-analog convertor integrated circuit (DAC) (MAX522) creating a voltage between 0 and $2.5 \mathrm{~V}$. This is conditioned with operational amplifiers (amplification and offset to create the negative voltage) to give a range from approximately $-14.5 \mathrm{~V}$ to $+14.5 \mathrm{~V}$. The DAC output value of the MAX522 is set with a

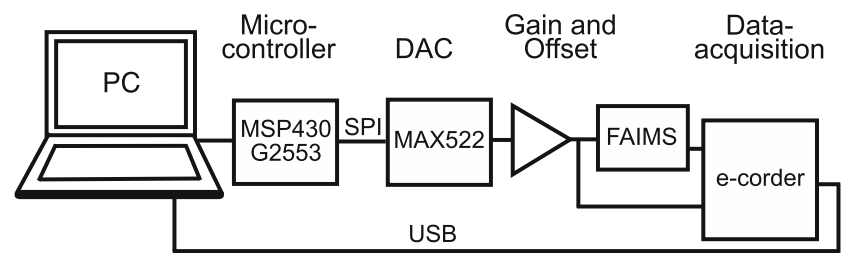

Fig. 2 Set-up employed for the implementation of the compensation voltage scan

microcontroller (MSP430G2553) via a serial peripheral interface (SPI) bus. This is accomplished with a software routine that runs on the microcontroller which was written in the computer language Forth. The microcontroller was connected to a PC (personal computer) via a USB-to-TTL cable. A graphical user interface (GUI) written in Python on the PC completes the set-up. As Forth is an interpreted computer language the microcontroller reacts to command strings send to it by the GUI program running on the $\mathrm{PC}$ without having to write special communication software for the microcontroller. The use of a microcontroller tethered in this way to a PC to control experimental systems is muss less expensive (typically less than $€ 50$ ) than using a commercial solution and highly flexible. More detail on this interactive approach to control experimental systems can be found in a previous publication [18].

The mobility scans were acquired with an e-corder data acquisition system, which we find easier to use than the LabVIEW set-up employed by Chavarria et al. [13] as the implemention of the measurement itself then does not require any programming by the user. The e-corder records voltage vs. time data. An acquisition rate of 20 measurements per second and an input span of $5 \mathrm{~V}$ was set (the voltage resolution of the system is at least 16 bits). In order to obtain the graphs of detector signal vs. compensation voltage the two signals were recorded in parallel on two channels. Following the acquisition the data was exported and then processed and graphically displayed in the correct way with a scientific data analysis software.

\section{Operating parameters}

In Fig. 3 FAIMS spectra for $11 \mathrm{ppm}_{(V / \mathrm{V})}$ of ethylene for different amplitudes of the rectangular pulse voltage up to $500 \mathrm{~V}$ are shown (for a pulse frequency of $1 \mathrm{MHz}$ and a duty cycle of $20 \%$ ). It can be seen that when no pulsing is applied a single peak is observed, which splits into two bands for increased pulse voltages. Note, that no peak was observed when only ambient laboratory air was passed through the device. Both peaks therefore originate from ethylene and were found to be linearly dependent on its concentration. According to Chupka et al. [17] the ion produced from ethylene by exposure to radiation with an energy of $10.5 \mathrm{eV}$ is $\mathrm{C}_{2} \mathrm{H}_{4}{ }^{+}$. One possible explanation for the presence of two peaks might be the partial formation of a water cluster (i.e. $\left[\mathrm{C}_{2} \mathrm{H}_{4}+\mathrm{H}_{2} \mathrm{O}\right]^{+}$) with 


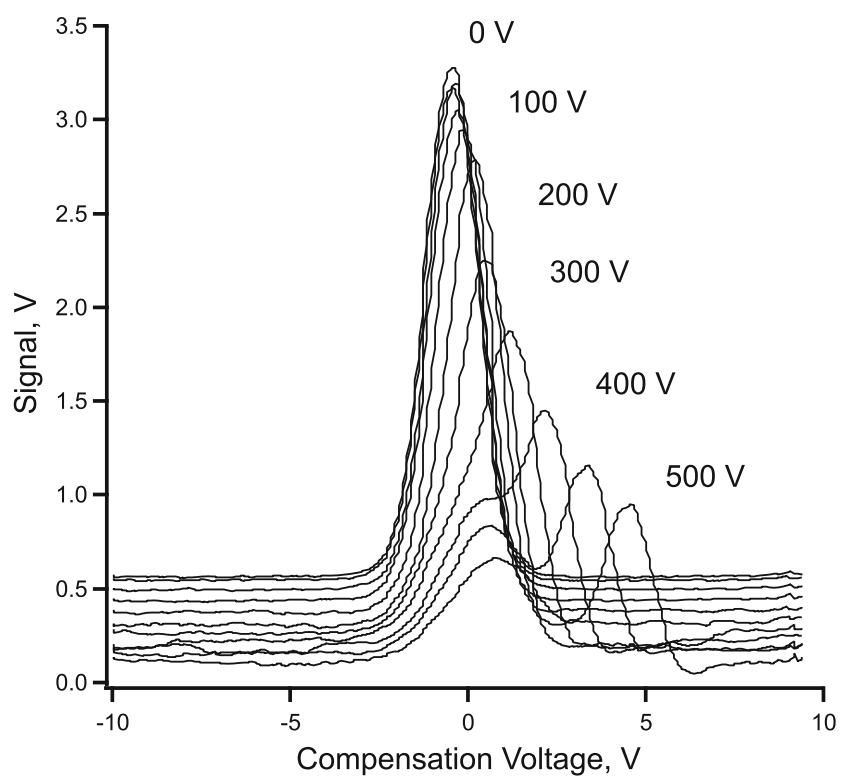

Fig. 3 Mobility spectra obtained for $11 \mathrm{ppm}_{(V / \mathrm{V})}$ ethylene in nitrogen for different amplitudes of the separation voltage between 0 and $500 \mathrm{~V}$ in steps of 50 V. Pulsation: $20 \%$ duty cycle and $1000 \mathrm{kHz}$. Gas flow rate: $9 \mathrm{~L} / \mathrm{min}$

humidity from the ambient air. When carrying out the experiment in nitrogen also two peaks with undistinguishable relative intensities were observed. As dry nitrogen still contains traces of water $(\leq 5 \mathrm{ppm}$ water according to the specification of the supplier) the formation of a water cluster is still a possibility, but a shift in the relative intensities would be expected. Another reason may be the formation of secondary species. Ceyer et al. in experiments designed to promote photoionization and collisions identified a host of secondary species, such as $\mathrm{C}_{3} \mathrm{H}_{5}{ }^{+}, \mathrm{C}_{4} \mathrm{H}_{7}{ }^{+},\left(\mathrm{C}_{2} \mathrm{H}_{4}\right)_{2}{ }^{+}$, with mass spectrometry [19]. It is therefore possible that the larger peak observed by us can be attributed to $\mathrm{C}_{2} \mathrm{H}_{4}{ }^{+}$, while the second peak may be due to one, or several unresolved, secondary species. On the other hand in tests with some other species (ethanol, benzene, toluene, acetone) similar secondary peaks were also observed, and such features are also present in the spectra for acetone and xylene reported by Chavarria et al. [13], which indicates that this could also be an instrumental artefact. While the power supply employed would allow higher voltages, it was found that $500 \mathrm{~V}$ is the maximum at which the pulse circuitry could be operated for extended periods of time without it breaking down, and this value was therefore adapted for the further studies.

The effect of the pulse frequency (at $500 \mathrm{~V}$ amplitude and a duty cycle of $20 \%$ ) on the height of the larger peak is shown in Fig. 4. The observed increase with frequency is expected as presumably the losses on the walls of the channel are diminished due to the reduced lateral movement. The maximum of $1 \mathrm{MHz}$ was dictated by the function generator employed, which has an upper limit of $1 \mathrm{MHz}$ for non-symmetrical rectangular waves. However, this also corresponds approximately

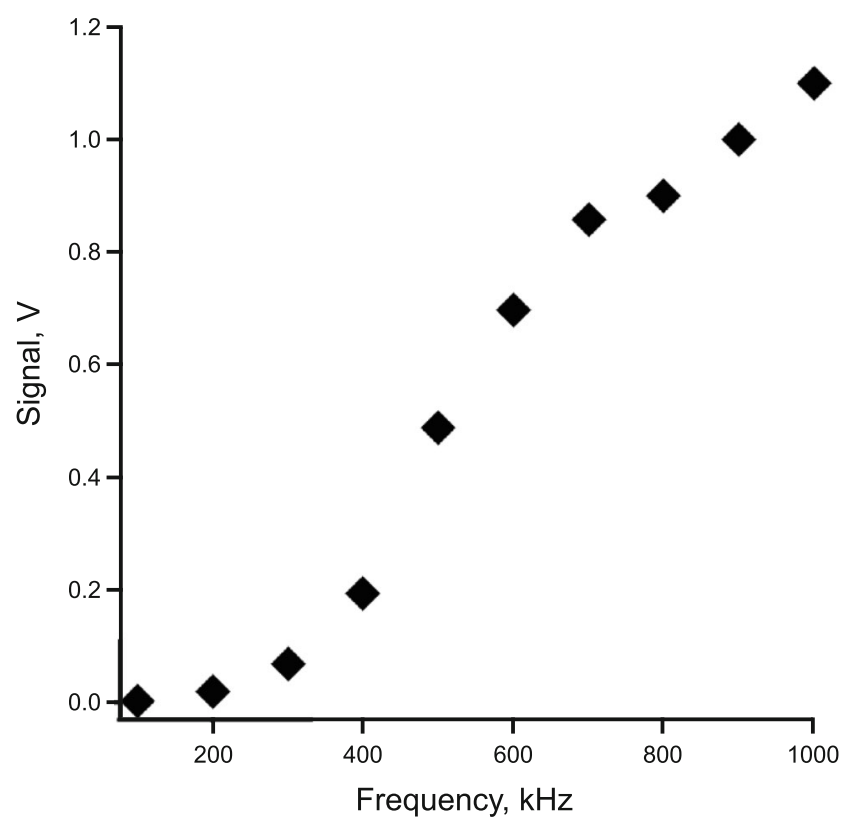

Fig. 4 Effect of the pulse frequency on the peak height for ethylene. Amplitude $500 \mathrm{~V}$. Other conditions as for Fig. 3. Each data point is the average from 3 scans

to the upper frequency limit of the pulse circuitry due to the finite transition time of the high voltage FETs (see Chavarria et al. for details [13]). Also investigated was the effect of the duty cycle of the applied rectangular wave on the signal (for a pulse voltage of $500 \mathrm{~V}$ and a frequency of $1 \mathrm{MHz}$ ). Duty cycles of $50 \%, 40 \%, 30 \%$ and $20 \%$ showed peak heights of $1.41 \mathrm{~V}$ at a compensation voltage $(\mathrm{CV})$ of $-1.26 \mathrm{~V}, 1.27 \mathrm{~V}$ at a $\mathrm{CV}$ of $1.95 \mathrm{~V}, 1.16 \mathrm{~V}$ at a CV of $3.77 \mathrm{~V}$ and $1.13 \mathrm{~V}$ at a CV of $4.56 \mathrm{~V}$. While the more symmetrical duty cycles gave higher sensitivities, this, of course, also imparts a decreased resolution. The gas flow rate also had an effect in that the best sensitivity (presumably due to reduced wall losses) and highest precision was obtained at the maximum flow rate of $9 \mathrm{~L} \cdot \mathrm{min}^{-1}$ possible with the set-up employed. A pulse rate of $1 \mathrm{MHz}$, with a duty cycle of $20 \%$ at $500 \mathrm{~V}$ amplitude, and the flow rate of $9 \mathrm{~L} \cdot \mathrm{min}^{-1}$ were therefore adopted for the experiments.

\section{Selectivity}

For ionization, the Krypton lamp with a radiation energy of $10.6 \mathrm{eV}$ was employed. This imparts a high degree of selectivity in that its radiation energy $(10.6 \mathrm{eV})$ is just high enough for ionization of ethylene (10.5 eV) [17], but other potentially present species with higher ionization energy will not be detected. These include $\mathrm{CO}_{2}$ with an ionization energy of $13.8 \mathrm{eV}$, acetylene with $11.4 \mathrm{eV}$ and $\mathrm{SO}_{2}$ with $12.3 \mathrm{eV}$ [20]. One potential interferent which may be present is ethanol. Therefore the response of the device to ethanol was examined. In Fig. 5 a mobility spectrum for a mixture of ethylene and 


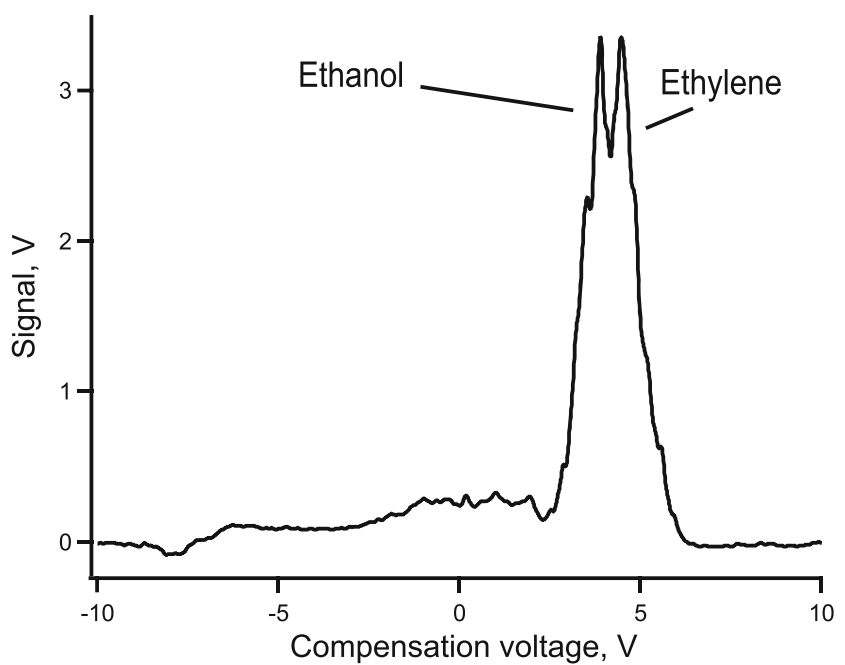

Fig. 5 Mobility scan for a mixture of ethylene with ethanol. Amplitude $500 \mathrm{~V}$. A small amount of ethanol was introduced to a stream of $11 \mathrm{ppm}_{(\mathrm{V} / \mathrm{V}}$ ethylene in nitrogen by bleeding in the headspace of $20 \%(v / v)$ ethanol in water. Other conditions as for Fig. 3

ethanol is shown. As can be seen, the peaks for the two species could not be separated fully. This will prevent accurate quantification of ethylene in presence of ethanol, and was therefore not attempted. However, under normal circumstances ethanol is not expected in fruit storage, and, on the other hand, the detection of ethanol in the mobility spectrum could also be useful as an indicator of spoilage.

The tolerance of the system to humidity was tested as this was deemed important in view of its potential agricultural application. In order to humidify the ethylene standard gas stream beyond the humidity of the laboratory air the gas mixture was passed through a Dreschel bottle filled with water. The humidity of the stream was measured with a humidity sensor placed after the FAIMS device as illustrated in Fig. 1. With and without water inside the bottle, the humidities of the stream were determined to be $60 \pm 4 \%$ and $32 \pm 1 \%$, respectively. It was found that the signals for the humidified stream were not significantly different to the ones obtained for the not humidified stream.

\section{Quantification}

A calibration curve was acquired for the concentration range from $670 \mathrm{ppb}_{(V / \mathrm{V})}$ to $67 \mathrm{ppm}_{(\mathrm{V} / \mathrm{V})}$ (14 points) from the peak heights of the larger of the two peaks. A linear response was obtained $(\mathrm{y}=(0.0888 \pm 0.0044) \mathrm{x}+(0.1013 \pm 0.0442)), \mathrm{x}=$ concentration in $\mathrm{ppb}$ ) with a correlation coefficient, $r$, of 0.9999 . The relative standard deviation for measurements at the concentration of $11 \mathrm{ppm}$ was found to be $4 \%$ by taking 3 scans within $90 \mathrm{~s}$. The limit of detection was determined as $200 \mathrm{ppb}_{(\mathrm{V} / \mathrm{V})}(3 \times$ standard deviation $)$.

\section{Determination of ethylene from ripening fruits}

Six types of climacteric fruit were bought from a local supermarket: apples, bananas, kiwi fruit, nectarines, pears and plums. Weighed amounts of whole fruit (383 g apple, $124 \mathrm{~g}$ banana, $500 \mathrm{~g}$ kiwi fruit, $729 \mathrm{~g}$ nectarine, $522 \mathrm{~g}$ pear and $355 \mathrm{~g}$ plum) were placed in separate plastic bags which were then filled with approximately $10 \mathrm{~L}$ of ambient air and sealed. Measurements were carried out after $24 \mathrm{~h}$ storage at room temperature. Two subsequent measurements were possible with the available volume before the bags were empty. The bags were then refilled with ambient air and the measurements repeated after another $24 \mathrm{~h}$. Bags were employed rather than containers with fixed walls as the bags shrink on extraction of air, and thus no dilution by air entering the container occurs. The resulting mobility spectra are shown in Fig. 6. In all cases pronounced ethylene peaks were found. The amounts of ethylene given off by the fruit are given in Table 1. The levels on the second day are higher than on the first day, which can be expected as the fruit are ripening. On the other hand, not too much can be read into these values as the levels of ethylene are vastly dependent on the degree of ripeness, the temperature and the type of fruit. Gwanpua et al. [21] quote values of $0.022-0.35 \mu \mathrm{L} \cdot \mathrm{kg}^{-1} \cdot \mathrm{h}^{-1}$ for unripe and $43.3-200 \mu \mathrm{L} \cdot \mathrm{kg}^{-1}$. $\mathrm{h}^{-1}$ for ripe apples, $0.42-121 \mu \mathrm{L} \cdot \mathrm{kg}^{-1} \cdot \mathrm{h}^{-1}$ for ripe kiwi fruit, $0.1-0.38 \mu \mathrm{L} \cdot \mathrm{kg}^{-1} \cdot \mathrm{h}^{-1}$ for unripe and $15-120 \mu \mathrm{L} \cdot \mathrm{kg}^{-1} \cdot \mathrm{h}^{-1}$ for ripe pears. Chillet et al. [22] state a value of $2-50 \mu \mathrm{L} \cdot \mathrm{kg}^{-1} \cdot \mathrm{h}^{-1}$ for ripening banana. The values obtained with the FAIMS detector generally fall within these ranges.

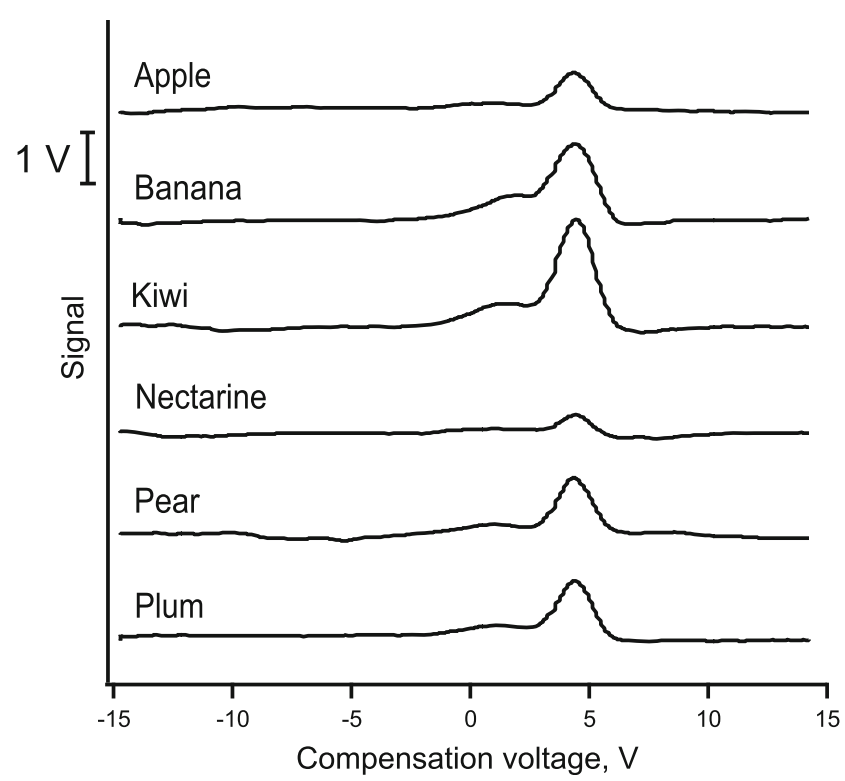

Fig. 6 Mobility scans for the gases given off by the fruit. Amplitude 500 V. Other conditions as for Fig. 3 
Table 1 Ethylene released from fruits on two consecutive days

\begin{tabular}{lcl}
\hline Type of fruit & $\begin{array}{l}\text { Day 1 } \\
\left(\mu \mathrm{L} \cdot \mathrm{kg}^{-1} \cdot \mathrm{h}^{-1}\right)\end{array}$ & $\begin{array}{l}\text { Day 2 } \\
\left(\mu \mathrm{L} \cdot \mathrm{kg}^{-1} \cdot \mathrm{h}^{-1}\right)\end{array}$ \\
\hline Apples & $8.46 \pm 0.44$ & $11.3 \pm 0.5$ \\
Bananas & $38.0 \pm 4.4$ & $56.6 \pm 1.6$ \\
Kiwi fruit & $6.92 \pm 0.26$ & $20.0 \pm 0.9$ \\
Nectarines & $0.93 \pm 0.12$ & $1.99 \pm 0.06$ \\
Pears & $8.7 \pm 1.2$ & $9.10 \pm 0.62$ \\
Plums & $12.8 \pm 0.3$ & $14.2 \pm 0.8$
\end{tabular}

The units refer to the volume of ethylene given off per $\mathrm{kg}$ of fruit per hour. Each value represents the average of two measurements. See the text for more details

\section{Conclusions}

It has been demonstrated that ethylene may be quantified with an easily constructed FAIMS device employing a UV lamp for ionization and that ethylene given off by climacteric fruit may be determined. The detection limit of $200 \mathrm{ppb}_{(V / \mathrm{V})}$ is better than that reported for an instrument based on a nondispersive absorbance measurement (20 ppm [23]), comparable to those reported for electrochemical detection (760 ppb [9], $40 \mathrm{ppb}$ [10]), but not as good as that reported for gas chromatography (0.4 ppb [7]) or a photoacoustic instrument (0.3 ppb [8]). On the other hand, the device is simpler and less expensive than the latter and more robust than the electrochemical devices, and may be an option for applications where ultimate sensitivity is not required.

Acknowledgements The authors acknowledge the financial support from the Development and Promotion of Science and Technology Talents Project of Thailand (DPST 532133).

Funding Information Open access funding provided by University of Basel. University of Basel and Development and Promotion of Science and Technology Talents Project of Thailand (DPST 532133).

\section{Compliance with ethical standards}

\section{Conflict of interest none.}

Open Access This article is licensed under a Creative Commons Attribution 4.0 International License, which permits use, sharing, adaptation, distribution and reproduction in any medium or format, as long as you give appropriate credit to the original author(s) and the source, provide a link to the Creative Commons licence, and indicate if changes were made. The images or other third party material in this article are included in the article's Creative Commons licence, unless indicated otherwise in a credit line to the material. If material is not included in the article's Creative Commons licence and your intended use is not permitted by statutory regulation or exceeds the permitted use, you will need to obtain permission directly from the copyright holder. To view a copy of this licence, visit http://creativecommons.org/licenses/by/4.0/.

\section{References}

1. Caprioli F, Quercia L (2014) Ethylene detection methods in postharvest technology: A review. Sens Actuator B-Chem 203:187-196

2. Hu B, Sun DW, Pu H, Wei Q (2019) Recent advances in detecting and regulating ethylene concentrations for shelf-life extension and maturity control of fruit: A review. Trends Food Sci Technol 91:66-82

3. Iannetta PPM, Laarhoven LJ, Medina-Escobar N, James EK, McManus MT, Davies HV, Harren FJM (2006) Ethylene and carbon dioxide production by developing strawberries show a correlative pattern that is indicative of ripening climacteric fruit. Physiol Plant 127(2): 247-259. https://doi.org/10.1111/j.1399-3054.2006.00656.x

4. Janssen S, Schmitt K, Blanke M, Bauersfeld ML, Wöllenstein J, Lang W (2014) Ethylene detection in fruit supply chains. Phil Trans R Soc A 372(2017):20130311

5. Barry CS, Giovannoni JJ (2007) Ethylene and fruit ripening. J Plant Growth Regul 26(2):143-159

6. Cristescu SM, Mandon J, Arslanov D, De Pessemier J, Hermans C, Harren FJM (2012) Current methods for detecting ethylene in plants. Ann Bot 111(3):347-360

7. Pereira L, Pujol M, Garcia-Mas J, Phillips MA (2017) Non-invasive quantification of ethylene in attached fruit headspace at 1 p.p.b. by gas chromatography-mass spectrometry. Plant J 91(1):172-183

8. Pathak N, Caleb OJ, Rauh C, Mahajan PV (2017) Effect of process variables on ethylene removal by vacuum ultraviolet radiation: application in fresh produce storage. Biosyst Eng 159:33-45

9. Zevenbergen MAG, Wouters D, Dam V-AT, Brongersma SH, Crego-Calama M (2011) Electrochemical sensing of ethylene employing a thin ionic-liquid layer. Anal Chem 83(16):6300-6307

10. Jordan LR, Hauser PC, Dawson GA (1997) Amperometric sensor for monitoring ethylene. Anal Chem 69(4):558-562

11. Jordan LR, Hauser PC, Dawson GA (1997) Portable trap-sensor system for monitoring low levels of ethylene. Analyst 122(8):811-814

12. Jordan LR, Hauser PC, Dawson GA (1997) Humidity and temperature effects on the response to ethylene of an Amperometric sensor utilizing a gold-Nafion electrode. Electroanalysis 9(15):1159-1162

13. Chavarria MA, Matheoud AV, Marmillod P, Liu Y, Kong D, Brugger J, Boero G (2017) High sensitivity field asymmetric ion mobility spectrometer. Rev Sci Instrum 88(3):035115

14. Eiceman GA, Karpas Z, Hill HHJ (2016) Ion mobility spectrometry. CRC Press, Boca Raton

15. Shvartsburg AA (2009) Differential ion mobility spectrometry. CRC Press, Boca Raton

16. Cross JH, Limero TF, Lane JL, Wung F (1997) Determination of ammonia in ethylene using ion mobility spectrometry. Talanta 45(1):19-23

17. Chupka WA, Berkowitz J, Refaey KMA (1969) Photoionization of ethylene with mass analysis. J Chem Phys 50(5):1938-1941

18. Furter JS, Hauser PC (2019) Interactive control of purpose built analytical instruments with forth on microcontrollers - A tutorial. Anal Chim Acta 1058:18-28

19. Ceyer ST, Tiedemann PW, Ng CY, Mahan BH, Lee YT (1979) Photoionization of ethylene clusters. J Chem Phys 70(5):2138-2144

20. https://webbook.nist.gov/chemistry/name-ser/

21. Gwanpua SG, Jabbar A, Tongonya J, Nicholson S, East AR (2018) Measuring ethylene in postharvest biology research using the laserbased ETD-300 ethylene detector. Plant Methods 14(1):105

22. Chillet M, De Lapeyre de Bellaire L, Hubert O, Mbéguié-AMbéguié D (2008) Measurement of ethylene production during banana ripening. Fruits 63(4):253-254

23. DeBiasio M, LeitnerR, Krall C, Krivec M, Wilk A, MizaikoffB, Waldner R, Starmans F, Maier D (2016). Ethylene gas sensing using nondispersive infrared spectroscopy. In: 2016 IEEE sensors. IEEE, pp 1-3

Publisher's note Springer Nature remains neutral with regard to jurisdictional claims in published maps and institutional affiliations. 